\title{
Partial reinforcement with a small number of acquisition trials: Pretraining and acquisition'
}

\author{
Garvin MeCain \\ ARLINGTON STATE COLLEGE
}

\begin{abstract}
One group of rats received four trials with 50\% reinforcement, another group received $100 \%$ reinforcement, a third group received no reinforcement. The usual PRE was obtained; in addition, the 100\% group was more resistant to extinction than the third group. The use of a small number of acquisition trials was considered both as a technique and in relation to some aspects of the frustration hypothesis.
\end{abstract}

\section{Problem}

This study is one of a series (McCain et al, 1962; McCain et al, 1963; McCain, 1965a; McCain, 1965b) in which a very small number of acquisition trials were used. The original purpose of these studies was to test the prediction from the frustration hypothesis (Amsel, 1958; Spence, 1960) that the partial reinforcement effect (PRE) would not occur until a substantial number of reinforcements have been given. In addition to its relation to the frustration hypothesis the present study had two objectives. First, a group which received no reinforcement was to be compared to reinforced groups, since it was conceivable that with the small number of acquisition trials reinforcement would not substantially influence performance. The second objective was to determine whether the results of the previous studies with a small number of acquisition trials were dependent on exploration of the runway prior to acquisition training. These two latter objectives are of interest independent of any particular theoretical interpretation since the use of a. small number of acquisition trials may be a useful approach to some other problems.

\section{Method}

Ninety-three naive 90-day-old albino rats were used. Nine Ss were dropped: two due to illness, four due to experimental error, and three (one from each group) on the basis that they had to be guided to the goal box on three of the four acquisition trials.

The straight alley was 36 in long, with a guillotine door 7 in from the goal box. The goal boxes were $L$ shaped, with a food cup arranged so that it could not be seen until $\mathrm{S}$ entered the goal box. The timer was started by a photoelectric cell 3 in from the proximal end of the alley and was stopped by a photoelectric cell 2 in from the goal box.

Ss were placed on $23 \mathrm{hr}$. deprivation on Day 1 and handled $1 \mathrm{hr}$. daily on Days 2 thru 13. Wet mash was available during the handling period. In contrast to earlier studies, none of the Ss explored either the test runway or any other runway prior to acquisition trials. On Day 14, Ss were divided into three groups on a random basis and fed for $20 \mathrm{~min} .24 \mathrm{hr}$. before they were to be run on Day 15.

Groups were formed on the basis of three reinforcement schedules: Group $C(N=27)$, four successive reinforced trials; Group $P(N=28)$, a NRNR reinforcement pattern; Group $O(N=29)$ was not reinforced on any trial. The four acquisition trials were followed by 12 extinction trials.

Ss failing to stop the timer within $30 \mathrm{sec}$. on acquisition or extinction trials were guided to the goal box and given a score of $30 \mathrm{sec}$. Ss remained in the goal box for $30 \mathrm{sec}$. on each acquisition trial and $15 \mathrm{sec}$. on each extinction trial, with a 5 sec. intertrial interval.

\section{Results and Diseussion}

An arcsin transformation (Winer, 1962) was used to normalize the data. In Fig. 1, the transformed data are plotted by individual trials during acquisition and by means of four trial blocks during extinction. Running speed for Group $O$ starts about the same as the other two groups but when a comparison is made on the basis of Acquisition Trials 3 and 4, Groups P $(\mathrm{p}<.01)$ and $C(p<.02)$ run significantly faster than Group $O$. These results plainly indicate that both consistent and intermittent reinforcement influenced performance, even with a very small number of trials; in this case the influence is evident after two trials. The vigorous performance on the early acquisition trials is of interest but space does not permit speculation. Whatever the initial cause of the rapid locomotion, in the absence of reinforcement the Ss do slow down.

The transformed extinction data were analyzed using a trend analysis. As may be seen in Fig. 1, Group C runs faster than Group $O$ until they reach about the same

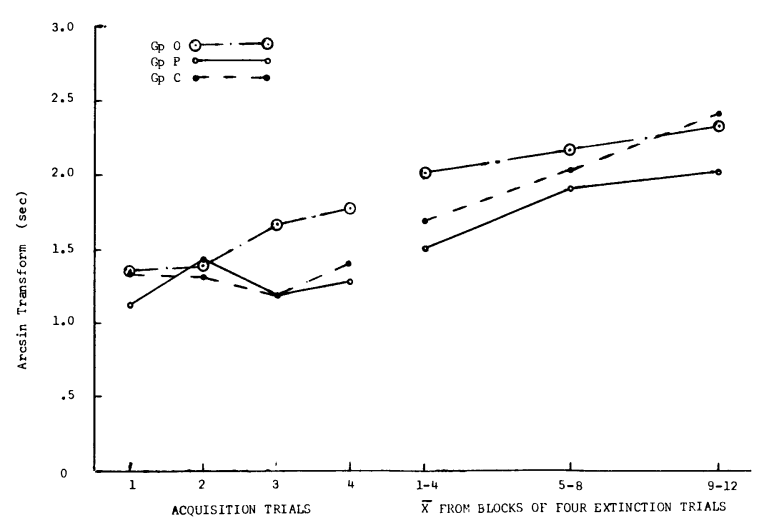

Fig. 1. Transformed running times for individual acquisition trials and blocks of four extinction trials. 
level of performance by the third block of extinction trials. The running times of both groups approach the maximum allowable time on the third block. There was a significant Groups $x$ Trials interaction $(p<.05)$; in addition, Group $C$ ran significantly faster than Group $O$ on the first block of extinction trials $(p<.005)$. Thus the effects of reinforcement were evident during a large portion of the extinction period.

Group $P$ runs significantly faster during extinction than either Group C $(t(53)=2.73 ; p<.01)$ or Group $O(t(55)=4.44 ; p<.001)$. The comparison of Groups $P$ and $\mathrm{C}$ agrees with findings from the earlier studies (McCain et al, 1962, and McCain, 1965a), the PRE can be achieved following a very limited number of acquisition trials. Further, the difference between Groups $\mathrm{P}$ and $\mathrm{C}$ indicates that the differences obtained between partial and consistent reinforcement groups, where only a very limited number of acquisition trials are used, do not depend on prior exploration of the test apparatus.

Studies in this series raise serious questions regarding those assumptions made in the frustration hypothesis which have led both Amsel (1958) and Spence
(1960) to conclude that the PRE would not occur after a very small number of training trials.

There is some question as to the possible effects of satiation in the present study. This problem has been examined in two studies which are in preparation as part of a paper covering several studies.

\section{References}

AMSE L, A. The role of frustrative nonreward in noncontinuous reward situations. Psychol. Bull., 1958, 55, 102-119.

McCAIN, G. Partial reinforcement with a small number of trials: Performance in extinction. Psychon. Sci., 1965a, 131-132.

McCAIN, G. Partial reinforcement with a small number of trials: Modified extinction procedures. Psychon. Sci., 1965b, 133-134. McCAIN, G., LOVE, NANCEY, \& GRUER, W. Extinction as a function of a small number of partially reinforced trials. Psychol. Rep., $1962,11,451-454$.

MCCAIN, G., REED, CLY, \& McCORMACK, L. Extinction after a small number of partial reinforcement trials. Psychol. Rep., $1963,13,300$.

SPENCE, K. W. Behavior theory and learning. Englewood Cliffs, N.J.: Prentice-Hall, 1960.

WINER, B. J. Statistical principles in experimental design. New York: McGraw-Hill, 1962.

Note

1. This study was supported by NIMH Grant MH-06981. Thanks are due to John Taylor Williams who ran the Ss.

\section{Comment}

Thompson (Psychon. Sci., 1965, 109-110) reports further evidence supporting his previous conclusion (J. exp. Anal. Behav., 1964, 7, 1-8) that increased fixed-ratio response requirements, on a bar reinforced by food or water, are associated with increasing response rates on a second (time-out) bar which temporarily removes both the $S^{D}$ and the reinforcement. In his efforts to reconcile this finding (dubbed the "FR-TO effect") with failures to demonstrate it by Zimmerman \& Ferster (J. exp. Anal. Behav., 1964, 7, 13-19), Thompson conspicuously avoids any mention of the many inextricably confounded variables in his 1964 (and presumably also his 1965) experiment, despite the fact that I had pointed to one of these confoundings as providing a likely alternative explanation for his results during his Master's oral examination almost two years ago. This alternative interpretation clearly needs to be made explicit, inasmuch as it apparently has escaped previous editorial reviewers (as well as readers), probably because of Thompson's failure to describe adequately his extensive 1964 pretraining procedure which produced the confounding.

In point of fact, one of the few conditions held constant for all of Thompson's (1964) animals was their extensive pretraining under conditions identical to the conventional operations for attaching positive secondary-reinforcing properties to his "time-out" stimulus. As a consequence, he begins by establishing a stimulus as a positive secondary reinforcer, and subsequently claims to be demonstrating "escape" behavior when the animal indicates a preference for that same stimulus over another associated with water (or food) reinforcement under a high fixed-ratio requirement!!

Admittedly, Thompson's (1965) cursory description of his birds' previous service in 'an experiment involving different colored key-lights and variableinterval schedules of reinforcement," so that "little preliminary training was necessary since the birds were not experimentally naive," suggests that in his 1965 report he had not followed his 1964 pretraining procedure. However, if his unspecified 1965 pretraining conditions had eliminated the secondary-reinforcement establishing operations for the TO stimulus, this most certainly should have been mentioned in view of its obvious bearing upon the appropriate interpretation to be attached to his FR-TO effect. In either case, these unspecified and seemingly haphazard changes in procedure render Thompson's characterization of his "replication" as "systematic" highly questionable even as compared with the type of procedure for which Sidman had originally adopted this label.

William F. Battig University of Maryland

(See page 258 for reply by D. M. Thompson) 